\title{
THE EFFECT OF GENDER ON UNIVERSITY TEACHERS' ICT USE
}

\author{
Manica Danko, Mitja Dečman, Damijana Keržič and Vida Zorko \\ University of Ljubljana, Slovenia
}

\begin{abstract}
Information communication technology (ICT) that is used in instruction has attracted the attention of researchers with many studies having looked at the factors affecting how university instructors apply it in their teaching. Yet little is known about whether the gender of university teachers can impact their ICT use. This research relies on quantitative data from a survey of 428 teachers at the University of Ljubljana in Slovenia to explore differences in pedagogical ICT use in terms of gender. The results show that gender positively correlates with ICT use and that particular ICT tools and their pedagogical uses are more frequent among female teachers whereas males scored higher for certain ICT-related attitudes. This implies that gender may be viewed as a predictor of certain types of and attitudes to ICT use in university instruction.
\end{abstract}

\section{KEYWORDS}

Higher Education, Instructional ICT Use, Gender

\section{INTRODUCTION}

Information communication technology (ICT) has made its way into the area of instruction within higher education (HE), with studies revealing that it is commonly used to enhance teaching practices (Collis and van der Wende, 2002, p. 29; Gaebel et al., 2014, pp. 24, 71). A large number of factors may affect teachers' use of ICT in the HE context and many are well explored. For instance, Al-Busaidi and Al-Shihi (2012) identify intention, attitude, perceived usefulness, ease of use, perceived risk, perceived behavioural control, social influence and facilitating conditions as factors that determine how satisfied academics will be with ICT and, more specifically, with learning management systems (LMSs). Their level of satisfaction will thus impact their intention to adopt and use LMSs. Similarly, Motaghian et al. (2013) claim that perceived usefulness, perceived ease of use and system quality affect university teachers' use of online learning systems, with perceived usefulness being the most decisive factor. Wang and Wang (2009) point out that the quality of the system and service together with self-efficacy are strongly associated with university teachers' use of online learning systems. Kocaleva et al. (2015) highlight effort expectancy and facilitating conditions, social influence and facilitating conditions as determinants of university teachers' intention to use new ICT.

However, this paper focuses on university teachers' gender given that much less literature on this factor can be found. Thus, the following research question guided the research: Is there any correlation between university teachers' gender and their self-reported educational use of ICT?

To answer the question, this study relies on quantitative data obtained from a survey conducted by the University of Ljubljana (UL) as part of the project "Digital UL - with innovative use of ICT towards excellence - DiUL" that aims to enhance and support flexible ICT-supported teaching approaches within the university. The DiUL survey explored pedagogical, technical and organisational aspects of ICT use at the UL. Its objective was to identify how ICT is being promoted in UL study programmes, which ICT-supported teaching methods and practices are in use, which ICT tools are adopted, and what the university's needs are with regard to technical, technological and organisational support. Findings of the DiUL survey will inform the development of innovative learning environments, the introduction of ICT-supported methods and pedagogical practices in the UL's study programmes.

This paper first reviews relevant literature on the effects of gender on instructional ICT use in HE. It then outlines the methodology employed in the research and presents the results. A discussion of the findings and their implications follows in the final section. 


\section{LITERATURE REVIEW}

Considerable research exists on the effect of teachers' demographic variables like gender, age and teaching experience on their ICT adoption (Rahimi and Yadollahi, 2011, p. 18). However, it primarily focuses on teachers in general. Much less literature is available on how these factors affect the ICT use of teachers in HE.

Research into the impact of gender on ICT use in modern society shows differences between males and females. For example, Broos (2005) reveals significant gender differences with regard to attitudes to ICT. Men hold positive attitudes to computers and the Internet whereas women display higher levels of computer anxiety. Moreover, men have greater computer experience and, compared to women, consider themselves as being ahead of others concerning computer or Internet use.

With respect to teachers, in the early 2000s Ilomäki (2011, p. 336) found differences between males and females who self-assessed their use of ICT. In most applications, male teachers evaluated their skills as being higher than their female colleagues. Yet, a more recent study of the digital competence of 2,477 upper secondary school teachers indicates a different trend. It shows that in this regard women have a higher mean score than men (Krumsvik et al., 2016, p. 157).

As for academic staff, the literature reveals differences between males and females, although the research is inconclusive. On one hand, certain studies conclude that gender differences do not exist. For example, while exploring how academic staff perceive the use of ICT at a university in Saudi Arabia, Alkhasawneh and Alanazy (2015, p. 494) find no significant gender-based differences among the staff. They believe that this is due to ICT use having become normalised in today's world. This is in line with the findings of a survey in India by Bhat and Bashir (2017) that reveals no significant differences between male and female university teachers with respect to gender, and that males and females have a similar attitude to ICT use. Similarly, Soydal et al. (2012, p. 287) analysed academic staff at a Turkish university and reveal that gender is mostly not a factor in e-learning readiness.

On the other hand, Soydal et al. note one exception, namely, confidence in using computers. Their research shows that males are more confident (2012, p. 287). Consistent with this finding, Agboola (2006, p. 5) finds a significant connection between gender and e-learning confidence: male lecturers have greater confidence than their female colleagues. Other gender differences are identified by Tena et al. (2016) who studied how e-learning has been adopted by various universities in Andalusia, Spain. They find that male lecturers have better ICT skills and knowledge of certain tools than their female counterparts. However, they also reveal that females use these tools more often in their teaching than males (2016, p. 33). Further differences between male and female university teachers were uncovered by Okazaki and Renda dos Santos (2012, p. 101). They carried out a study that included three Brazilian universities to explore how faculty members adopt e-learning tools. The results show that males and females differ with regard to certain causal relationships. For the male faculty members, perceived usefulness more strongly shapes their attitude to e-learning and, similarly, their feeling of ease of use more strongly impacts their perceived usefulness of e-learning.

Thus, it could be tentatively concluded that gender does not often play a role in HE ICT use. When it does, however, confidence, better ICT skills, along with the causal relationships "perceived usefulness $\rightarrow$ positive attitude" and "ease of use $\rightarrow$ perceived usefulness" can more often be ascribed to males. Frequent instructional use of ICT tools is more likely to be associated with female HE teachers.

\section{METHODOLOGY AND DATA}

The purpose of this study was to explore the effects of gender on teachers' ICT use. To realise this research objective, we relied on data collected in a survey conducted at the UL as part of the DiUL project in 2017. Participants were academic staff from 23 faculties and 3 academies. The invitation to participate in the survey was sent by email. All 2,682 teachers were invited to participate. The survey comprised 64 questions in the form of individual statements measured with ordinal scales using a 5-point Likert-type scale. The responses were scaled as follows: from 1 - "disagree very strongly" to 5 - "agree very strongly" (to express agreement), from 1 - "never" to 5 - "very often" (to describe how often they use ICT in teaching), and from 1 - "once a year/never" to 5 - "every day" (to describe how often they use ICT at home). 
The survey was responded to by 960 teachers; 53 records where more than seven values (half the total) were missing were removed. In the pre-processed dataset, some values $(<1 \%)$ were still missing. We replaced them with the default parameters used in the Expectation-Maximisation (EM) algorithm in SPSS. The final sample comprised 428 complete responses, representing a $16 \%$ response rate. To achieve a confidence level of $95 \%$ indicating that the true value is within $\pm 5 \%$ of the measured value, 337 responses are required, meaning this condition was met.

Teachers were also asked about certain demographic data such as gender, age, educational qualification, classification of their educational field, academic title and the faculty they work at. Among all of the academic staff, $40 \%$ were female and $60 \%$ were male. However, the valid and complete records in our possession were for an equal number of male and female respondents (Table 1).

Table 1. Demographic profile of 428 respondents

\begin{tabular}{lcc}
\hline & $\mathrm{N}$ & Percentage \\
\hline Gender & 214 & $50 \%$ \\
Female & 214 & $50 \%$ \\
Male & & \\
\hline Age & 91 & $22.7 \%$ \\
$21-40$ & 166 & $41.3 \%$ \\
$41-50$ & 73 & $18.2 \%$ \\
$51-55$ & 71 & $17.7 \%$ \\
$55+$ & & \\
\hline
\end{tabular}

To detect any gender differences considering different survey indicators, a Mann-Whitney U rank-based nonparametric test was applied. The Mann-Whitney U test or Wilcoxon-Mann-Whitney test is a rank-based nonparametric test used to determine differences between two groups on a continuous or ordinal dependent variable. This test was feasible since we have ordinal dependent variables, the independent variable is categorical with two groups (gender) and the observations are independent of each other (Field, 2007, p. 542). In the next step the feature selection method was used. This method is usually applied in machine learning to reduce the number of input variables. The method calculates the relationship between each input variable and the target value in a predictive or classification model. In our case, the target value was gender, therefore binary classification was the task. We used Naïve Bayes which can achieve relatively good results with classification problems despite the assumption of independent predictors (Novaković et al., 2011). Completely independent variables are very rarely obtained in real life.

\section{EMPIRICAL RESULTS}

Using the Mann-Whitney U rank test, we detected statistically significant differences between the means of values for males and females for certain indicators shown in Table 2. Significant differences in median values and mean rank values are found in the rows where the p-value is below 0.05 (marked in bold). 
Table 2. Indicators with statistically significant differences between males and females

\begin{tabular}{|c|c|c|c|c|c|c|c|}
\hline Indicator & MrM & $\mathrm{MrF}$ & MdnM & $\mathrm{MdnF}$ & $\mathrm{p}$ & $\mathrm{U}$ & $\mathrm{Z}$ \\
\hline Use of presentation slides & 149.72 & 230.61 & 5 & 5 & $<0.001$ & 26,274 & 3.770 \\
\hline Use of online video lectures & 189.76 & 229.24 & 2 & 3 & 0.001 & 25,967 & 3.420 \\
\hline Use of online resources (books, articles etc.) & 195.62 & 226.60 & 4 & 4 & 0.007 & 25,415 & 2.719 \\
\hline Use of LMSs & 201.10 & 215.00 & 4 & 4 & 0.220 & 22,970 & 1.227 \\
\hline Use of online bibliographic databases & 181.82 & 239.45 & 3 & 4 & $<0.001$ & 28,101 & 5.026 \\
\hline $\begin{array}{l}\text { Use of online communication tools (email, forums } \\
\text { etc.) }\end{array}$ & 191.95 & 231.22 & 5 & 5 & $<0.001$ & 26,401 & 3.928 \\
\hline $\begin{array}{l}\text { Use of online social networking services } \\
\text { (Facebook, Twitter etc.) }\end{array}$ & 202.30 & 215.86 & 1 & 1 & 0.198 & 23,146 & 1.288 \\
\hline $\begin{array}{l}\text { Use of collaboration tools (wikis, Google Drive } \\
\text { etc.) }\end{array}$ & 204.98 & 224.02 & 4 & 4 & 0.086 & 24,934 & 1.717 \\
\hline $\begin{array}{l}\text { Personal use of ICT for entertainment (music, } \\
\text { movies, etc.) }\end{array}$ & 206.54 & 215.29 & 5 & 5 & 0.456 & 23,064 & 0.746 \\
\hline Personal use of ICT to obtain information, news & 218.89 & 205.08 & 5 & 5 & 0.194 & 20,905 & -1.299 \\
\hline $\begin{array}{l}\text { Personal use of ICT for communication (email, } \\
\text { chat, videocalls etc.) }\end{array}$ & 209.03 & 214.00 & 5 & 5 & 0.474 & 22,784 & 0.716 \\
\hline Personal use of ICT for social networking & 189.08 & 209.92 & 2 & 3 & 0.061 & 21,873 & 1.870 \\
\hline
\end{tabular}

MrM - Mean rank (male), MrF - Mean rank (female), MdnM - Median (male); MdnF - Median (female);

p - asymptotic p-value; U - Mann-Whitney U; z - Standardised Test Statistic

To further examine gender differences in the teachers' responses to the survey questions, feature selection methods were employed. These methods are commonly used in data pre-processing to reduce the number of features by selecting a subset of variables which efficiently describes the data according to a certain criterion. In feature selection methods it is considered that the features describing the data are independent. These methods allow us to rank features regarding their relevance for a predicted (class) variable. Different indices may be used to calculate the dependency between the variable and the predicted variable (class), and to then rank variables by their relevance (Chandrashekar and Sahin, 2014; Jović et al., 2015).

In our case, each unit (a teacher) is described with 64 ordinal variables (from 1 to 5) - responses to the questionnaire statements and gender as the target binary class. The investigation proceeded using Orange, an open source machine learning and data visualization platform (Demšar et al., 2013). We calculated different indices, namely information gain, gain ration and Gini decrease, compared the obtained ranks and combined them to create a new rank of features. Different results subsets of the highest-ranking features were then tested with a Naïve Bayes classifier. The performance of different variants of the subset was measured using a 10-fold stratified cross-validation (Novaković et al., 2011). Figure 1 presents the classification accuracy of various numbers of the selected ranked features. The classification for the best subset of features is presented as a confusion matrix that shows the percentage classification. The final set of 13 relevant variables, in order of their significance, contains:

- Use of online bibliographic databases

- Use of ICT in lectures

- I can become a promoter of innovative ICT use in my department/chair/faculty

- Use of ICT in seminar work, problem-based or project-based learning

- Use of online communication tools (e-mail, online forums ...)

- Use of ICT for revising knowledge

- Use of presentation slides

- Use of ICT for designing the study process

- I am able to improve my ICT skills for use in the study process

- I can use ICT in my academic research (e.g. conducting research, report writing, presenting findings)

- Applying ICT in the study process requires more time for planning and preparation

- Use of online social networking services (Facebook, Twitter ...)

- Use of online video lectures 


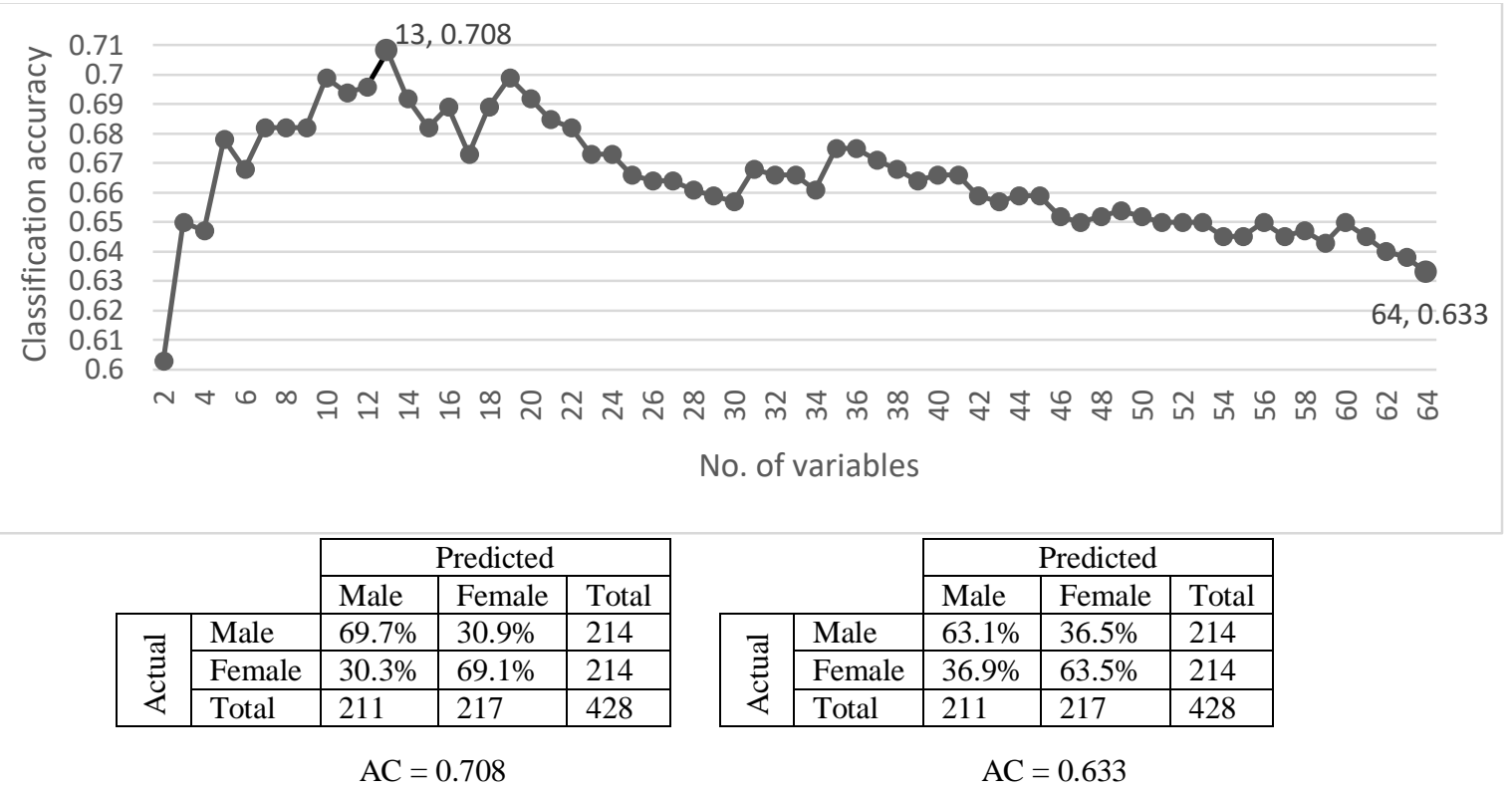

Figure 1. Classification accuracy (AC) depending on the number of ranked values selected. Confusion matrices of the performance of the classification Nave Bayes model based on the chosen subset features (left) and on the entire set features (right)

The median, mean and results of the Mann-Whitney $U$ test for the best subset of variables is presented in Table 3. Indicators where the mean for females is greater than for males are shown in bold. Only one of the indicators (Use of online social networking services (Facebook, Twitter ...)) reveals no significance in the median values and mean rank values $(\mathrm{p}<0.05)$.

Table 3. Median, mean and Mann-Whitney test for indicators from the best subset

\begin{tabular}{|c|c|c|c|c|c|c|c|}
\hline \multirow[b]{2}{*}{ Indicator } & \multicolumn{3}{|c|}{ Median } & \multicolumn{3}{|c|}{ Mean } & \multirow{2}{*}{$\begin{array}{l}\text { Mann- } \\
\text { Whitney } \\
\text { Sig.* }\end{array}$} \\
\hline & M & $\mathrm{F}$ & Total & M & $\mathrm{F}$ & Dif. (M - F) & \\
\hline Use of online bibliographic databases & 3 & 4 & 3 & 3.3 & 3.9 & -0.6 & 0.000 \\
\hline Use of ICT in lectures & 4 & 4 & 4 & 3.8 & 4.2 & -0.4 & 0.000 \\
\hline $\begin{array}{l}\text { I can become a promoter of innovative ICT use in } \\
\text { my department/chair/faculty }\end{array}$ & 3 & 2 & 3 & 3.0 & 2.5 & 0.5 & 0.000 \\
\hline $\begin{array}{l}\text { Use of ICT in seminar work, problem-based or } \\
\text { project-based learning }\end{array}$ & 4 & 4 & 4 & 3.3 & 3.6 & -0.3 & 0.001 \\
\hline $\begin{array}{l}\text { Use of online communication tools (e-mail, } \\
\text { online forums ...) }\end{array}$ & 5 & 5 & 5 & 4.3 & 4.6 & -0.3 & 0.000 \\
\hline Use of ICT for revising knowledge & 3 & 4 & 3 & 3.2 & 3.6 & -0.4 & 0.000 \\
\hline Use of presentation slides & 5 & 5 & 5 & 4.2 & 4.6 & -0.4 & 0.000 \\
\hline Use of ICT for designing the study process & 4 & 4 & 4 & 3.7 & 4.0 & -0.3 & 0.000 \\
\hline $\begin{array}{l}\text { I am able to improve my ICT skills for use in the } \\
\text { study process }\end{array}$ & 4 & 4 & 4 & 3.9 & 3.6 & 0.3 & 0.000 \\
\hline $\begin{array}{l}\text { I can use ICT in my academic research (e.g. } \\
\text { conducting research, report writing, presenting } \\
\text { findings) }\end{array}$ & 4 & 4 & 4 & 4.3 & 4.1 & 0.2 & 0.001 \\
\hline $\begin{array}{l}\text { Applying ICT in the study process requires more } \\
\text { time for planning and preparation }\end{array}$ & 3 & 3 & 3 & 3.0 & 2.7 & 0.3 & 0.013 \\
\hline $\begin{array}{l}\text { Use of online social networking services } \\
\text { (Facebook, Twitter ...) }\end{array}$ & 1 & 1 & 1 & 1.8 & 2.0 & -0.2 & 0.198 \\
\hline Use of online video lectures & 2 & 3 & 3 & 2.4 & 2.8 & -0.4 & 0.001 \\
\hline
\end{tabular}

M - Male, F - Female

*Statistically significant difference in median values and mean rank values at $p<0.05$ 


\section{DISCUSSION AND CONCLUSION}

The main objective of this study was to examine UL teachers' use of ICT instructional tools in terms of gender. Our analysis of their responses is conclusive: female instructors use ICT more often than their male colleagues whereas males showed higher self-reported ICT skills and confidence in instructional use. This agrees with the findings of Tena et al. (2016).

Female UL teachers more often use presentation slides, online video lectures, resources, bibliographic databases, communication tools and social networking services to support and enhance their teaching. There are also some pedagogical activities in which female UL teachers more often apply ICT. These include lectures, problem presentation in problem-based or project-based learning, revising knowledge, and designing the study process. In sum, female teachers scored higher in a number of instructional ICT uses. These findings may suggest that female UL teachers are more diligent because applying ICT in the study process generally requires greater time for instructional design and preparation.

However, the male respondents scored higher than the females in their attitudes to ICT use. They seem to be more digitally savvy than the females since more of them feel they could become promoters of innovative ICT use in their institutions. More of them are reportedly able to improve their ICT skills for use in the study process. This is in line with the findings of Agboola (2006, p. 5) and Soydal et al. (2012, p. 287) who also identified higher confidence levels among male academic staff. Moreover, our findings suggest that more males believe they can use ICT in their academic research. These findings may mean that male teachers feel confident in their ICT skills but are more reluctant to use ICT in their teaching.

One area where we did not find gender differences is personal ICT use. Here, our results agree with the findings of Alkhasawneh and Alanazy (2015, p. 494) and Bhat and Bashir (2017) who did not identify any important gender differences among academic staff. We may therefore conclude that personal use of digital technology has become normalised for both genders.

We believe that these findings can assist by informing the planning and implementation of pedagogical support at the UL, for which gender differences must be considered. To help increase the confidence levels of female teachers, we suggest that staff development and training provide forms of recognition such as e.g. teaching excellence awards for those adopters of ICT with a significant positive impact on teaching and learning experience and results. To increase motivation among males to adopt ICT, incentives could be provided to share good teaching practices where ICT is found to enhance the teaching quality. Further, training to encourage ICT use by males and females must be provided in the workplace. Such training should be based on a needs analysis to provide for the specific requirements of individual teachers so that they can better meet the criteria.

This research has a few limitations. One is that other demographic data were not included in the analysis, e.g. age, educational attainment level, and years of service. Another is the problem of generalisation as the sample is from a single university. As the research formed part of a UL project, data from other universities were not available. The data set should be broader and incorporate additional universities in the analysis. Future research on university teachers' ICT use could entail a larger sample that includes more universities and explore the correlation between gender and other demographic data. Another interesting research area could involve comparing instructional ICT use across different disciplines, study programmes and courses.

\section{ACKNOWLEDGEMENT}

The research was supported by the University of Ljubljana within the project "Digital UL - with innovative use of ICT towards excellence - DiUL" (Digitalna UL - z inovativno uporabo IKT do odličnosti). The project was financed by the Republic of Slovenia and the European Union under the European Social Fund. 


\section{REFERENCES}

Agboola, A. K., 2006. Assessing the awareness and perceptions of academic staff in using e-learning tools for instructional delivery in a post-secondary institution: A case study. The Public Sector Innovation Journal, Vol. 11, No. 3, article 4.

Al-Busaidi, K. and Al-Shihi, H., 2012. Key factors to instructors' satisfaction of learning management systems in blended learning. Journal of Computing in Higher Education, Vol. 24, pp. 18-39.

Alkhasawneh, S. and Alanazy, S., 2015. Adopt ICT among Academic Staff in Aljouf University: Using UTAUT Model. Mediterranean Journal of Social Sciences, Vol. 6, No. 1, pp. 490-494.

Bhat, S. A. and Bashir, M., 2018. Measuring ICT orientation: Scale development \& validation. Education and Information Technologies, Vol. 23, No. 3, pp. 1123-1143. DOI:10.1007/s10639-017-9656-4

Broos, A. M. A., 2005. Gender and Information and Communication Technologies (ICT) Anxiety: Male Self-Assurance and Female Hesitation, CyberPsychology \& Behavior, Vol. 8, No. 1, pp. 21-31.

Chandrashekar, G. and Sahin, F., 2014. A survey on feature selection methods. Computers and Electrical Engineering, Vol. 40, pp. 16-28.

Collis, B. and van der Wende, M., 2002. Models of Technology and Change in Higher Education. Center for Higher Education Policy Studies (CHEPS), Enschede. http://www.utwente.nl/cheps/documenten/ictrapport.pdf

Demšar, J., Curk, T., Erjavec, A., Gorup, Č., Hočevar, T., Milutinovič, M., Možina, M., Polajnar, P., Toplak, M., Starič, A., Štajdohar, M., Umek, L.,Žagar, L., Žbontar, J., Žitnik, M. and Zupan, B., 2013. Orange: Data Mining Toolbox in Python, Journal of Machine Learning Research, Vol. 4, pp. 2349-2353.

Field, A., 2009. Discovering Statistics Using SPSS (3 ${ }^{\text {rd }}$ edition). SAGE Publications Ltd.

Gaebel, M., Kupriyanova, V., Morais, R., Colucci, E., 2014. E-learning in European higher education institutions: Results of a mapping survey conducted in October-December 2013. European University Association, Brussels. http://old.eua.eu/Libraries/publication/e-learning_survey

Ilomäki, L., 2011. Does Gender Have a Role in ICT Among Finnish Teachers and Students? Scandinavian Journal of Educational Research, Vol. 55, pp. 325-340.

Jović, A., Brkic, K. and Bogunovic, N., 2015. A review of feature selection methods with applications. MIPRO 2015, 25-29 May 2015, Opatija: Croatia, pp. 1200-1205. DOI:10.1109/MIPRO.2015.7160458

Kocaleva, M., Stojanovic, I. and Zdravev, Z., 2015. Model of e-Learning Acceptance and Use for Teaching Staff in Higher Education Institutions. International Journal of Modern Education and Computer Science, Vol. 7, No. 4, pp. $23-31$.

Krumsvik, R. J, Jones, L. Ø., Øfstegaard, M. and Eikeland, O. J., 2016. Upper secondary school teachers' digital competence: Analysed by demographic, personal and professional characteristics. Nordic Journal of Digital Literacy, Vol. 11, No. 3, pp. 143-164.

Novaković, J., Strbac, P. and Bulatović, D., 2011. Toward optimal feature selection using ranking methods and classification algorithms. Yugoslav Journal of Operations Research, Vol. 21, No. 1, pp. 119-135.

Motaghian, H., Hassanzadeh, A. and Moghadam, D. K., 2013. Factors affecting university instructors' adoption of web-based learning systems: Case study of Iran. Computers \& Education, Vol. 61, pp. 158-167.

Okazaki, S. and Renda dos Santos, L.M., 2012. Understanding E-Learning Adoption in Brazil: Major Determinants and Gender Effects. International Review of Research in Open and Distributed Learning, Vol. 13, pp. 91-106.

Rahimi, M. and Yadollahi, S., 2011. ICT use in EFL classes: A focus on EFL teachers' characteristics. World Journal of English Language, Vol. 1, No. 2, pp. 17-29.

Soydal, İ., Alır, G. and Ünal, Y., 2011. Are Turkish Universities Ready for E-learning: A Case of Hacettepe University Faculty of Letters. Information Services \& Use, Vol. 31, pp. 281-291.

Tena, R., Almenara, J. C. and Osuna, J. B., 2016. E-learning of Andalusian University's lecturers. Turkish Online Journal of Educational Technology, Vol. 15, No. 2, pp. 25-37.

Wang, W. and Wang, C., 2009. An empirical study of instructor adoption of web-based learning systems. Computers \& Education, Vol. 53, No. 3, pp. 761-774. 